\title{
Gastric Emptying and Release of Incretin Hormones after Glucose Ingestion in Humans
}

Jörg Schirra, Martin Katschinski, Claudia Weidmann, Thomas Schäfer, Uwe Wank, Rudolf Arnold, and Burkhard Göke

Clinical Research Unit of Gastrointestinal Endocrinology and Department of Gastroenterology and Endocrinology, Philipps-University, 35033 Marburg, Germany

\begin{abstract}
This study investigated in eight healthy male volunteers $(a)$ the gastric emptying pattern of 50 and 100 grams of glucose; (b) its relation to the phase of interdigestive motility (phase I or II) existing when glucose was ingested; and (c) the interplay between gastric emptying or duodenal perfusion of glucose (1.1 and $2.2 \mathrm{kcal} / \mathrm{min}$; identical total glucose loads as orally given) and release of glucose-dependent insulinotropic peptide (GIP), glucagon-like peptide-1(7-36)amide (GLP-1), $\mathrm{C}$-peptide, insulin, and plasma glucose. The phase of interdigestive motility existing at the time of glucose ingestion did not affect gastric emptying or any metabolic parameter. Gastric emptying of glucose displayed a power exponential pattern with a short initial lag period. Duodenal delivery of glucose was not constant but exponentially declined over time. Increasing the glucose load reduced the rate of gastric emptying by $27.5 \%(P<0.05)$ but increased the fractional duodenal delivery of glucose. Both glucose loads induced a fed motor pattern which was terminated by an antral phase III when $\sim 95 \%$ of the meal had emptied. Plasma GLP-1 rose from basal levels of $\sim 1$ pmol/liter to peaks of $3.2 \pm 0.6$ pmol/liter with 50 grams of glucose and of 7.2 $\pm 1.6 \mathrm{pmol} /$ liter with 100 grams of glucose. These peaks occurred 20 min after glucose intake irrespective of the load. A duodenal delivery of glucose exceeding $1.4 \mathrm{kcal} / \mathrm{min}$ was required to maintain GLP-1 release in contrast to ongoing GIP release with negligibly low emptying of glucose. Oral administration of glucose yielded higher GLP-1 and insulin releases but an equal GIP release compared with the isocaloric duodenal perfusion. We conclude that (a) gastric emptying of glucose displays a power exponential pattern with duodenal delivery exponentially declining over time and (b) a threshold rate of gastric emptying of glucose must be exceeded to release GLP-1, whereas GIP release is not controlled by gastric emptying. (J. Clin. Invest. 1996. 97:92103.) Key words: antroduodenal coordination - enteroinsular axis • gastrointestinal motility $\bullet$ glucagon-like peptide-1 - glucose-dependent insulinotropic peptide
\end{abstract}

This work was presented in part at the Meeting of the American Gastroenterological Association on 14 May 1995 and published in abstract form (1995. Gastroenterology. 108:A1004 and A980).

Address correspondence to Dr. M. Katschinski, Department of Gastroenterology, Baldingerstr. 1, 35033 Marburg, Germany. Phone: 6421-282714; FAX: 6421-288924.

Received for publication 15 June 1995 and accepted in revised form 27 September 1995.

J. Clin. Invest.

(C) The American Society for Clinical Investigation

0021-9738/96/01/0092/12 \$2.00

Volume 97, Number 1, January 1996, 92-103

\section{Introduction}

The glycemic response to meals is primarily controlled by the delivery of carbohydrates from the stomach into the duodenum and the consecutive release of insulin in response to absorbed glucose. Both mechanisms are subject to regulation by the physical and chemical properties of ingested nutrients and by gut hormones and neurotransmitters.

An interesting observation was the outcome of oral glucose tolerance tests yielding a remarkable intra-individual variability (1). This was explained by the hypothesis that the velocity of the initial phase of glucose emptying from the stomach may depend on the grade of interdigestive antral motor activity at the time of glucose ingestion (2). In contrast, after intraduodenal perfusion of glucose, glucose plasma levels were not affected by the preceding interdigestive phase (2). After the initial emptying phase, the rate of gastric emptying of carbohydrate-containing liquids was suggested to be calibrated precisely at $\sim 2 \mathrm{kcal} / \mathrm{min}(3,4)$.

Recent studies have challenged the concept of an initial phase-dependent and subsequent linear, energy-constant gastric emptying of glucose. Phase-related changes in gastric emptying of nonnutrient liquids have less impact on emptying rates with increasing volumes of ingestion (5). The rate of initial emptying of liquids correlates with the volume of the meal independently of the preceding interdigestive phase (5). Moreover, in another study, energy delivery to the duodenum was not constant for different loads but correlated with meal volume and energy density (6). Gastric emptying of glucose was faster after dietary supplementation with glucose for $3 \mathrm{~d}$ (7). All these findings argue against a preset constant rate of gastric emptying of glucose. This emptying pattern is still a matter of conjecture.

Glucagon-like peptide-1-(7-36)amide (GLP-1) ${ }^{1}$ and glucose-dependent insulinotropic peptide (GIP) are the major hormonal mediators regulating postprandial insulin release. Both peptides are released from endocrine cells in the intestinal mucosa after ingestion of carbohydrates and enhance postprandial insulin release from the pancreatic $\beta$ cell $(8-10)$. Therefore, both hormones fulfill the criteria of incretin hormones (10). GLP-1 decreases postprandial glucose plasma levels by enhancing insulin secretion, lowering glucagon release, and stimulating insulin-independent glucose disposal in peripheral tissues $(11,12)$. Moreover, exogenous GLP-1 inhibits gastric emptying of liquid meals $(13,14)$. This suggests that GLP-1 could be a hormonal regulator of gastric emptying of carbohydrates.

1. Abbreviations used in this paper: AUC, area under the curve; CCK, cholecystokinin; GIP, glucose-dependent insulinotropic peptide; GLP-1, glucagon-like peptide-1; IR, immunoreactive; PEG, polyethylene glycol. 
Whereas many studies have focused on the biological effects of GLP-1, the mechanisms controlling its release remain to be elucidated. These mechanisms are of particular interest since peak plasma levels occur in the early postprandial period (9), independent of contact of nutrients with the majority of GLP-1-synthesizing L cells located in the ileum and colon (15, 16).

Therefore, the aim of this study was to investigate $(a)$ the gastric emptying pattern of glucose; $(b)$ its relation to the preceding interdigestive phase; $(c)$ the antroduodenal motor pattern accompanying gastric emptying; and $(d)$ the interplay between gastric emptying or duodenal perfusion of glucose, release of GIP and GLP-1, insulin release, and the resulting glycemic response.

\section{Methods}

Subjects. Eight healthy male volunteers, $24-28$ yr old and within $10 \%$ of ideal body weight, participated in the studies. None of them had a family history of diabetes mellitus; none were taking medication; and none suffered from gastrointestinal symptoms or any systemic disease including diabetes mellitus. The studies were approved by the Ethical Committee of the Medical Faculty of the Philipps-University of Marburg. Written informed consent was obtained from all participants.

Experimental procedure. All studies were performed after an overnight fast. In the first series, the subjects swallowed an eightlumen duodenal and a one-lumen gastric tube with their final position fluoroscopically checked. The gastric tube with its tip positioned in the antrum was used for sampling postprandial gastric contents to determine concentrations of the meal marker and glucose. The duodenal tube incorporated two antral sideholes $(2 \mathrm{~cm}$ apart $)$ and five duodenal sideholes ( $2 \mathrm{~cm}$ apart). The distal antral sidehole and the proximal duodenal sidehole were separated by $5 \mathrm{~cm}$. The two antral sideholes, the third and fourth sidehole, located in the duodenal bulb, and the sixth and seventh sidehole, located in the descending duodenum, were used for perfusion manometry. Through the fifth sidehole located adjacent to the papilla of Vater, the nonabsorbable marker phenol red $(300 \mathrm{mg} /$ liter in $0.154 \mathrm{~mol} /$ liter saline) was perfused at $2 \mathrm{ml} / \mathrm{min}$. The eighth lumen was used for fractional sampling of duodenal contents from the vicinity of the ligament of Treitz.

The correct position of the duodenal probe across the pylorus was monitored throughout the study by measuring the transmucosal potential difference at the distal antral and the most proximal duodenal port (17). These sideholes were perfused with $0.154 \mathrm{M}$ saline from separate, and therefore electrically isolated, reservoirs and acted as flowing saline electrodes as well as pressure recording channels. The saline infusions were connected via salt agar bridges $(1 \mathrm{M} \mathrm{KCl}$ in $3 \%$ agar) and balanced calomel half-cells to the input terminals of two high-impedance electrometers (Biomedical Engineering Dept., Academisch Ziekenhuis, Utrecht, The Netherlands). The common reference electrode was a cutaneous electrocardiogram electrode placed at the right upper arm and connected to each electrometer. A difference between the antral and duodenal transmucosal potential difference of at least $15 \mathrm{mV}$ indicated correct position of the tube across the pylorus (17).

The antral and duodenal motility recording channels were perfused at a rate of $0.3 \mathrm{ml} / \mathrm{min}$ using a low-compliance pneumohydraulic pump (Arndorfer Medical Specialists, Greendale, WI). Data were simultaneously recorded on a multichannel chart recorder (Beckman Instruments, Schiller Park, IL) and stored in the memory of an IBM PC. Data were sampled and digitized at $4 \mathrm{~Hz}$.

In the first series, four experiments were performed on each subject in random order. Experiments in individual subjects were separated by intervals of at least $1 \mathrm{wk}$. With the subjects comfortably lying in a semirecumbent position, duodenal perfusion of phenol red and continuous gastric aspiration were started. After 30-60 min of equili- bration, gastric aspiration was discontinued, and each subject consumed either 50 or 100 grams of glucose dissolved in $400 \mathrm{ml}$ of water yielding osmolalities of 773 and 1,610 mosmol/liter, respectively. These liquid meals were drunk within 2 min either during gastric and duodenal motor quiescence (phase I) at least 5 min after cessation of duodenal phase III activity or during active phase II (i.e., at least five antral contractions during the preceding $10 \mathrm{~min}$ ). Each glucose solution contained $800 \mathrm{mg}$ polyethylene glycol 4000 (PEG) as nonabsorbable meal marker. After the glucose drink, gastric and duodenal samples were taken in 5-min periods in the first $30 \mathrm{~min}$ and in 10-min periods for a further $150 \mathrm{~min}$. The first gastric sample was saved $5 \mathrm{~min}$ after meal ingestion. At each time point, $20-30 \mathrm{ml}$ of gastric contents was aspirated and mixed by agitation; a 2-ml sample was kept for analysis and stored on ice, with the remainder returned immediately to the stomach. 7-8-ml samples of duodenal contents were collected on ice during each sampling period. After $180 \mathrm{~min}$, gastric contents were completely aspirated. To optimize recovery of PEG and glucose during this aspiration procedure the stomach was lavaged with $100 \mathrm{ml}$ of $0.154 \mathrm{M}$ saline. Antroduodenal motility was continuously recorded throughout the experiment.

To compare hormone release to oral and duodenal glucose loads, two additional experiments with duodenal perfusion of glucose were performed in each subject. In this second series, the subjects swallowed a one-lumen duodenal tube with its tip positioned in the distal part of the descending duodenum. A $12.5 \%$ glucose solution $(0.5$ $\mathrm{kcal} / \mathrm{ml}, 773 \mathrm{mosmol} / \mathrm{liter}$ ) was duodenally perfused at $2.2 \mathrm{ml} / \mathrm{min}(1.1$ $\mathrm{kcal} / \mathrm{min})$ and $4.4 \mathrm{ml} / \mathrm{min}(2.2 \mathrm{kcal} / \mathrm{min})$ for $180 \mathrm{~min}$ delivering total glucose loads of 50 and 100 grams, respectively.

In all experiments, blood samples were drawn through an indwelling venous catheter $15 \mathrm{~min}$ and immediately before the meal or before the start of duodenal perfusion and 5, 10, 15, 20, 30, 45, 60, 90, 120,150 , and $180 \mathrm{~min}$ after the end of glucose ingestion or the start of duodenal perfusion. Plasma glucose and the immunoreactivities of GLP-1, GIP, insulin, and C-peptide were determined in each sample. Blood was collected in ice-chilled EDTA tubes containing 1,000 kallikrein inhibitory units aprotinin $/ \mathrm{ml}$ of blood and centrifuged immediately. The plasma was stored at $-80^{\circ} \mathrm{C}$ until assayed.

Determinations and analysis of gastric emptying data. Gastric and duodenal fluid outputs were measured to the next milliliter. Duodenal and gastric samples were analyzed for concentrations of PEG and phenol red. Moreover, gastric samples were analyzed for concentration of glucose to determine the emptying pattern of glucose itself.

PEG concentrations were determined turbidimetrically by a modified method of Hyden (18). Phenol red concentration was measured according to Hobsley and Silen (19). Glucose concentrations in gastric samples were measured using the hexokinase enzymatic reagent (Boehringer Mannheim, Mannheim, Germany) after deproteinization with perchloric acid. Validation experiments revealed a linear increase of the extinction at $365 \mathrm{~nm}$ in parallel with the glucose concentration in gastric juice. To correct for inter-individual differences of the matrix of gastric juice, the kit was gauged with interdigestive gastric juice sampled in each experiment before ingestion of glucose. The slope of the regression line characterizing the relation between extinction and gastric glucose concentration was $11.9 \pm 0.2 \mathrm{mg} \times \mathrm{dl}^{-1} \times$ $\delta \mathrm{E}^{-1}($ mean $\pm \mathrm{SEM})$ and did not significantly differ between experimental sets or subjects.

The measurement of gastric emptying was performed according to Malagelada et al. (20). Flow rates passing the duodenal sampling site were calculated based on the known infusion rate of phenol red and its concentrations at the infusion and sampling ports. The rate of PEG passage at the duodenal sampling site was calculated from the products of PEG concentrations in duodenal juice and duodenal flow rates. The amount of PEG retention in the stomach was calculated by subtracting the cumulative amount of marker recovered at each time point at the duodenal sampling site from the total amount of marker recovered during the whole experiment. The volume retention in the stomach was calculated by dividing the amount of PEG in the stomach by the gastric PEG concentration. Multiplying the gastric volume 
by the measured gastric glucose concentration yielded the amount of glucose retained in the stomach. This amount of glucose was expressed as a percentage of the total glucose recovered during the $3 \mathrm{~h}$ of the experiment. Total recovery of glucose was $99.7 \pm 3 \%$ (mean \pm SEM) and did not significantly differ between experimental sets or subjects. The volume of gastric contents being emptied into the duodenum during each sampling period was calculated from the amount of PEG reaching the duodenal aspiration port and the mean gastric concentration of PEG during each interval. Gastric secretory output during each sampling period was calculated on the basis of volume movements across the pylorus and volume sampled assuming no absorption of the meal in the stomach (20).

Shapes $(\beta)$ and velocity constants $(k)$ of the emptying curves were calculated for each experiment and each subject using nonlinear least squares regression fitting of the power exponential equation $f(t)=$ $e^{(-k t)^{\wedge} \beta}$ to the data as described previously (21). Derived from this equation the delivery of glucose into the duodenum (kilocalories per minute) is given by the formula: $f^{\prime}(t)=\beta(-k)^{\beta} \times t^{(\beta-1)} \times e^{(-k t)^{\wedge} \beta} \times$ recovered amount of glucose (kcal). Delivery rates of the meal marker PEG to the duodenum were correspondingly determined.

The lag period of glucose emptying as the time to achieve maximal emptying velocity was calculated as defined by Siegel (reference $22): t(\operatorname{lag})=(\ln \beta) / k)$. To assess the goodness of fit of the fitted nonlinear emptying curves, the fraction of variance in the data which can be accounted for by the fitted curve was computed for each individual emptying curve using the formula: $R^{2}=1-$ (residual sum of squares/total sum of squares), where the total sum of squares is $n-1$ times the square of the standard deviation of the observed fractions (21).

Phenol red determinations in gastric aspirates proved phenol red reflux of duodenal contents into the stomach to be absent or negligible $(<2 \%$ on average).

Analysis of motility tracings. Analysis of contractile events was computer assisted applying validated software (23). Only peaks with amplitudes of at least $10 \mathrm{mmHg}$ and durations of at least $2 \mathrm{~s}$ were considered true contractions (23). The interdigestive period with phase II activity, the preprandial 10-min period, and the postprandial period were analyzed separately. Antral phase III was defined as the occurrence of regular contractions at a frequency of $\geqslant 2.5 / \mathrm{min}$ for at least $2 \mathrm{~min}$ in the antrum and associated with sequential phase III activity in the duodenum. The time from glucose ingestion until occurrence of the first antral phase III indicating recurrence of interdigestive motility was determined. This time was subdivided into five intervals (quintiles) of equal duration for further analysis. If no phase III occurred within the recording period, the calculated $95 \%$ emptying time was taken. Amplitude ( $\mathrm{mmHg}$ ), duration (s), frequency of contrac- tions, and motility indexes were calculated separately for antrum, duodenal bulb, and descending duodenum by averaging the values derived from the two channels recording from each segment. The frequency of contractions was expressed as the number of peaks per 10 min. Motility index was determined as area under the contractions and expressed in $\mathrm{mmHg} \cdot \mathrm{s} \cdot \mathrm{min}^{-1}$. The antroduodenal coordination (24) was determined between the distal antral and the most proximal duodenal recording site and was expressed as the sum of coordinated antral contractions per $10 \mathrm{~min}$. An antral contraction was considered coordinated with a subsequent duodenal one if both peaks occurred within a time window of $5 \mathrm{~s}$.

Determinations and assays. Plasma immunoreactivities of insulin, C-peptide, and GIP were analyzed by commercially available radioimmunoassay kits (Biermann, Bad Nauheim, Germany). Plasma glucose concentrations were measured using a glucose autoanalyzer by the glucose oxidase method (YSI 1500 G; Schlag Company, BergischGladbach, Germany). Immunoreactive (IR) GLP-1 was measured using the specific polyclonal antibody GA 1178 (Affinity Research, Nottingham, United Kingdom) (25). It exhibits $100 \%$ reactivity with GLP-1 (1-36)amide and the truncated GLP-1 (7-36)amide. Immunoreactivities were extracted from plasma samples on C-18 cartridges using acetonitrile for elution of samples. The detection limit of the assay was $2 \mathrm{fmol} /$ tube. The antiserum did not cross-react with GIP, pancreatic glucagon, glicentin, oxyntomodulin, or GLP-2. Intra- and inter-assay coefficients of variation were 3.4 and $10.4 \%$, respectively.

Statistical analysis. All values were presented as mean \pm SEM. Time course of motility parameters was expressed by determining contraction frequencies and motility indexes for the interdigestive period with phase II activity, the preprandial interdigestive $10 \mathrm{~min}$, and the postprandial five quintiles until occurrence of phase III. Time course of plasma hormones and glucose was represented by the 2 interdigestive values before glucose ingestion and 11 values after meal ingestion or during duodenal perfusion, respectively. Increments of plasma hormones and glucose were calculated as integrated incremental values over basal (area under the response curve). Basal levels were determined as the mean of the two preprandial values. Time course of gastric retention and duodenal delivery of glucose was presented as mean \pm SEM of fitted data. All samples were first tested for normality of distribution by the Kolmogoroff-Smirnoff test. Differences between experimental sets for integrated plasma hormone and glucose levels, motility parameters, and gastric emptying data were analyzed by two-way repeated measures ANOVA using motility phase and amount of glucose ingested as factors. When this analysis indicated that the interdigestive phase or the glucose load elicited different responses, a Student-Newman-Keuls multicomparison test was performed. Metabolic responses to oral and duodenal glucose loads

Table I. Parameters of Gastric Emptying and Duration of Motility Patterns after Oral Ingestion of 50 or 100 Grams of Glucose in Interdigestive Phase I or II

\begin{tabular}{|c|c|c|c|c|}
\hline Parameter & Phase I/50 grams & Phase II/50 grams & Phase I/100 grams & Phase II/100 grams \\
\hline$k\left(\min ^{-1}\right)$ & $0.020 \pm 0.002$ & $0.020 \pm 0.001$ & $0.014 \pm 0.001 *$ & $0.015 \pm 0.001 * \frac{7}{*}$ \\
\hline Slope $\beta$ & $1.27 \pm 0.08$ & $1.20 \pm 0.07$ & $1.19 \pm 0.09$ & $1.20 \pm 0.11$ \\
\hline Lag period (min) & $12.8 \pm 3.9$ & $12.8 \pm 4.5$ & $23.3 \pm 5.5$ & $20.8 \pm 7.5$ \\
\hline $50 \%$ Retention $(\mathrm{min})$ & $41.4 \pm 5.9$ & $36.9 \pm 3.0$ & $54.7 \pm 5.0 * \ddagger$ & $51.5 \pm 5.5^{* \ddagger}$ \\
\hline $5 \%$ Retention (min) & $135.3 \pm 18.4$ & $127.4 \pm 7.6$ & $196.8 \pm 21.1 * \ddagger$ & $190.3 \pm 25.2 * \neq$ \\
\hline Gastric secretory volume $(\mathrm{ml})^{\S}$ & $376.4 \pm 57.8$ & $359.6 \pm 59.1$ & $423.5 \pm 69.7$ & $413.5 \pm 96.5$ \\
\hline Duodenally delivered volume $(\mathrm{ml})^{\S}$ & $687.3 \pm 45.9$ & $708.3 \pm 57.9$ & $743.1 \pm 69.6$ & $762.4 \pm 95.1$ \\
\hline Time to phase III (min) & $132 \pm 19(n=5)$ & $128 \pm 14(n=8)$ & 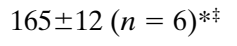 & $168 \pm 6(n=7)^{* \ddagger}$ \\
\hline Percent retention at phase III & $4.3 \pm 2.3(n=5)$ & $6.4 \pm 1.6(n=8)$ & $8.7 \pm 2.3(n=6)$ & $5.4 \pm 1.1(n=7)$ \\
\hline Postprandial quintiles (min) & $30.6 \pm 3.2$ & $25.4 \pm 2.7$ & $37.4 \pm 3.7$ & $33.6 \pm 1.1$ \\
\hline Interdigestive phase II (min) & $59.9 \pm 14.6$ & $72.8 \pm 13.5$ & $57.9 \pm 12.1$ & $65.6 \pm 8.6$ \\
\hline
\end{tabular}

Gastric emptying parameters were calculated using power exponential fitting according to Elashoff et al. (21). Mean \pm SEM. $n=8 .{ }^{\S}$ Cumulative values over 180 min. ${ }^{*} P<0.05$ vs. phase $\mathrm{I} / 50$ grams, ${ }^{*} P<0.05$ vs. phase $\mathrm{II} / 50$ grams. 
were compared by one-way repeated-measures ANOVA and Student-Newman-Keuls multicomparison test. Integrated values of IRGLP-1, IR-GIP, and glucose delivery into the duodenum during the first postprandial hour over basal were tested for significant influences on the integrated incremental insulin response during this period using linear regression analysis procedures. Differences were considered significant for $P<0.05$.

\section{Results}

Gastric emptying of glucose. In the postprandial study period of $180 \mathrm{~min}$, gastric emptying of glucose was close to complete in all subjects. The parameters of glucose emptying did not differ from those of PEG emptying. The results of gastric emptying of the glucose solutions containing 50 or 100 grams in identical volumes are shown in Table I and Fig. 1.50 and 100 grams of glucose were emptied in an exponential manner with a short initial lag period $(\beta>1)$. The measured emptying data fitted well to the power exponential equation with a median $R^{2}$ of 0.973 and 25 th and 75 th percentiles of 0.972 and 0.991 estimating goodness of fit for the nonlinear emptying curves. Ingestion of glucose in interdigestive phase I or II had no effect on velocity or pattern of subsequent gastric emptying. This finding especially held true for the initial $30 \mathrm{~min}$. Corresponding to the exponential emptying pattern, the rate of glucose delivery into the duodenum was not constant but exponentially declined over time (Fig. $1 \mathrm{~B}$ ). Compared with 50 grams, glucose retention in the stomach was prolonged after ingestion of 100 grams; the velocity constant $k$ decreased by $27.5 \%$ (Table I). This was mainly due to the reduced rate of gastric emptying in the first $30 \mathrm{~min}$ as indicated by reduced deliveries of the meal marker PEG and gastric volume into the duodenum during this period with 100 grams of glucose (Figs. $1 C$ and $2 C$ ). After $80 \mathrm{~min}$, deliveries of PEG and after $100 \mathrm{~min}$, deliveries of gastric volume following 100 grams of glucose surpassed the values obtained with 50 grams (Figs. $1 C$ and $2 C$ ). However, the shape $\beta$ of emptying curves remained unchanged with 50 and 100 grams (Table I). This implies that increasing the glucose load reduces the velocity of emptying but does not affect its pattern.

After ingestion of 50 and 100 grams of glucose, total gastric secretory volumes as well as total volume delivered to the duodenum did not differ significantly (Table I). The delay in volume delivery to the duodenum during the first $60 \mathrm{~min} \mathrm{ac}$ counted for the greater volume remaining in the stomach from 30 to $150 \mathrm{~min}$ after ingestion of 100 grams compared with 50 grams of glucose (Fig. 2, $B$ and $C$ ). The rate of caloric delivery into the duodenum was raised after ingestion of 100 grams of glucose over the whole emptying period as compared with 50 grams (Fig. $1 B$ ). This held true even in the first $30 \mathrm{~min}$ with reduced duodenal delivery of PEG (Fig. $1 C$ ) because of consistently elevated gastric glucose concentrations (Fig. $2 A$ ).

Antroduodenal motility. Oral glucose loads of 50 and 100 grams induced a fed motor pattern. In 26 of 32 experiments, a phase III of antroduodenal motility occurred, indicating reappearance of interdigestive motility (Table I). Independent of the amount of ingested glucose, phase III occurred after $\sim 95 \%$ of the meal had emptied. In the six experiments without phase III activity, emptying of glucose was more prolonged with mean gastric glucose retention at $180 \mathrm{~min}$ amounting to $17.6 \pm 4.1 \%$ (mean \pm SEM).

The durations of postprandial quintiles and interdigestive
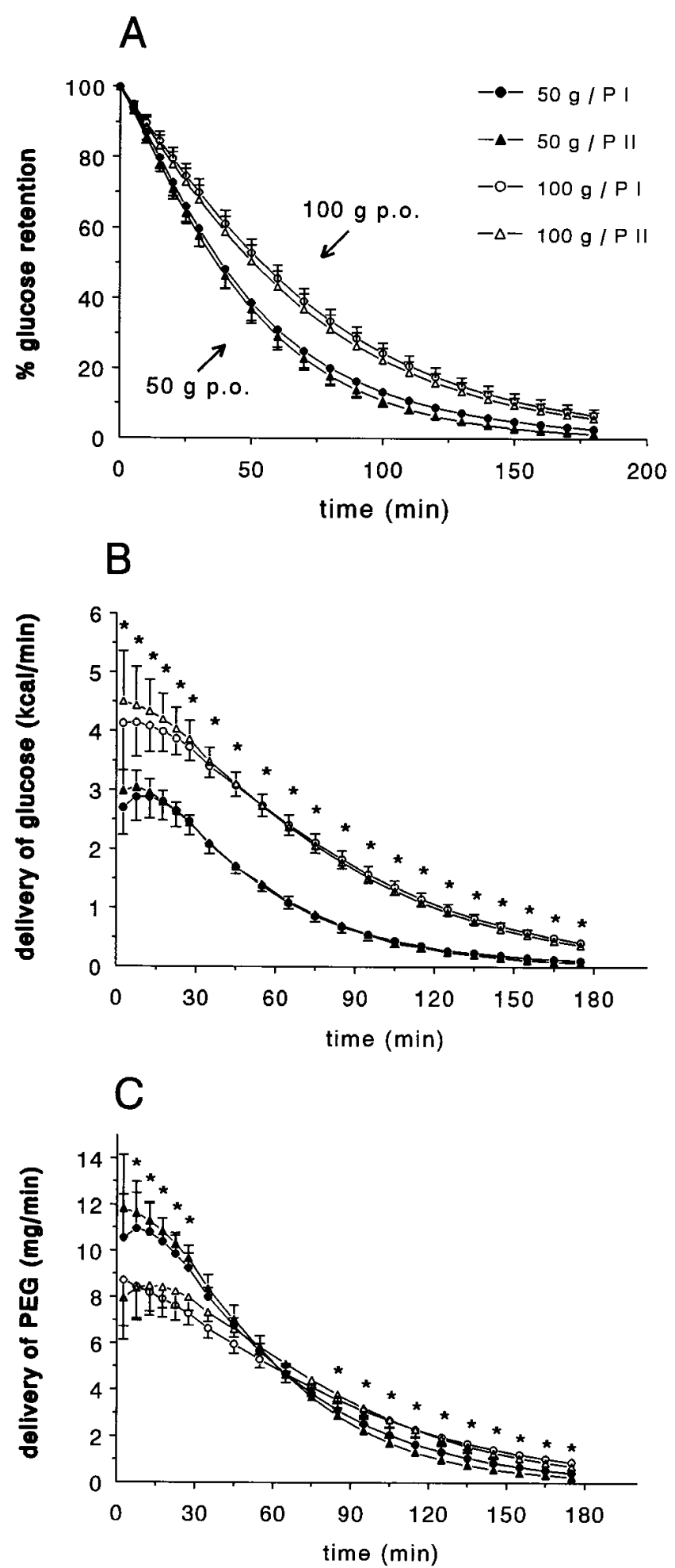

Figure 1. Gastric retention of glucose $(A)$ and delivery of glucose $(B)$ and the nonabsorbable meal marker PEG $(C)$ into the duodenum after oral ingestion of $400-\mathrm{ml}$ meals of 50 and 100 grams of glucose in interdigestive motility phase I $(P I)$ or phase II $(P I I)$ in eight volunteers. An identical amount of PEG was added to each meal. Mean \pm SEM. $* P<0.05$ for significant differences between experiments with 50 and 100 grams of glucose. For further statistical analysis, see Table I. 

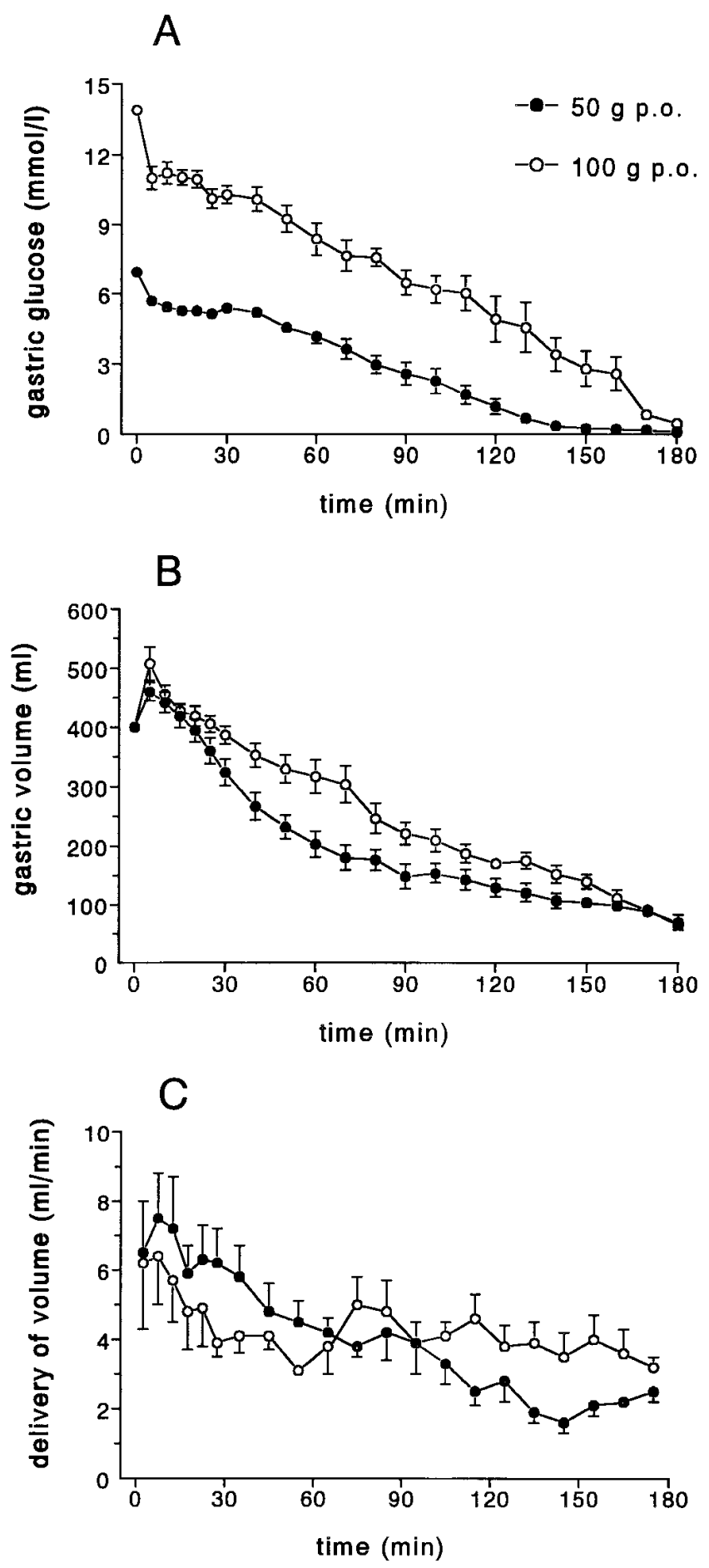

Figure 2. Gastric glucose concentration $(A)$, total gastric volume $(B)$, and delivery of volume into the duodenum $(C)$ after ingestion of 50 and 100 grams of glucose in eight volunteers. Mean \pm SEM. The gastric glucose concentrations were significantly higher $(P<0.001)$ until 160 min with 100 grams compared with 50 grams. The areas under the curves (AUC) from 30 to $150 \mathrm{~min}$ for total gastric volumes $(B)$ were significantly different $(2288.5 \pm 185.7 \mathrm{ml} * 120 \mathrm{~min}$ after 50 grams vs. $3193.5 \pm 201.2 \mathrm{ml} * 120 \mathrm{~min}$ after 100 grams of glucose; $P=0.0015)$. After ingestion of 100 grams compared with 50 grams, the volumes delivered to the duodenum $(C)$ were smaller during the first $60 \mathrm{~min}$ $(272.5 \pm 28.9 \mathrm{ml}$ vs. $348.5 \pm 30.6$; AUC; $P=0.0123)$ and greater from 100 to $180 \mathrm{~min}(306.5 \pm 18.8 \mathrm{ml}$ vs. $187.7 \pm 20.5 \mathrm{ml}$; AUC; $P=0.0012)$. phase II periods are listed in Table I. Fig. 3 shows the time course of contraction frequencies. In the antrum, contraction frequencies were significantly reduced after glucose ingestion during the first four quintiles compared with the interdigestive period. Thereafter, they increased significantly during the last quintile before appearance of phase III. In the duodenal bulb, postprandial contraction frequencies increased during the fifth quintile compared with the first three (50 grams) and the first two (100 grams) quintiles, respectively. However, there was no change compared with interdigestive motility. In the descending duodenum, no significant changes of contraction frequencies were observed. In no part of the antroduodenal segment did contraction frequencies discriminate between ingestion of 50 and 100 grams of glucose. Time courses of motility indexes and contraction frequencies were very similar, amplitudes and durations of contractions did not change with glucose ingestion (data not shown). The frequency and percentage of antral contractions coordinated to duodenal peaks as an index of propagation across the antroduodenal junction were significantly diminished after ingestion of 50 grams of glucose during the second and third postprandial quintile (Fig. 4). After 100 grams of glucose, this inhibition already occurred during the first quintile and persisted until the fourth (Fig. 4). Thus, in contrast to the parameters describing antral and duodenal motility separately, the antroduodenal coordination discriminated between glucose intakes of 50 and 100 grams. No motility parameter was influenced by the preceding interdigestive phase.

Plasma hormones and glucose. Fig. 5 shows the time courses of plasma glucose and the immunoreactivities of insulin, GIP, and GLP-1 after oral glucose ingestion. C-peptide release into the circulation corresponded to insulin release (data not shown). There was a significant dose-dependent increase of all metabolic parameters after intake of 100 compared with 50 grams of glucose. Postprandial plasma levels of all parameters did not differ if glucose was consumed in interdigestive phase I or II (Fig. 5). GLP-1 levels rose in a dose-dependent manner from basal levels of $\sim 1 \mathrm{pmol} /$ liter to peak levels of $3.2 \pm 0.6 \mathrm{pmol} / \mathrm{liter}$ after ingestion of 50 grams of glucose and to peak levels of $7.2 \pm 1.6 \mathrm{pmol} / \mathrm{liter}$ after 100 grams of glucose, respectively. After both doses, peak levels were achieved $20 \mathrm{~min}$ after glucose intake. Thereafter, GLP-1 levels declined sharply in parallel with decreasing glucose delivery into the duodenum (Fig. 6, $A$ and $B$ ). 60 min after ingestion of 50 grams and 120 min after ingestion of 100 grams of glucose, GLP-1 levels returned to basal, i.e., preprandial, values. When GLP-1 immunoreactivities returned to basal values, caloric delivery of glucose into the duodenum amounted to $1.4 \pm 0.1 \mathrm{kcal} / \mathrm{min}$ after 50 grams and to $1.1 \pm 0.1 \mathrm{kcal} / \mathrm{min}$ after 100 grams of glucose. These findings suggest the existence of a threshold of caloric delivery into the duodenum which must be exceeded to stimulate measurable release of GLP-1 into the circulation (Fig. 6, $A$ and $B$ ). With both 50 (45 min postprandially) and 100 grams of glucose (90 min postprandially), the minimal caloric delivery eliciting GLP-1 release amounted to $1.8 \pm 0.1 \mathrm{kcal} / \mathrm{min}$.

GIP plasma levels rose from basal to peak levels within 15$20 \mathrm{~min}$ and remained elevated throughout the emptying period (Fig. 5). In contrast to GLP-1, the peak levels reached after ingestion of 50 grams of glucose were not different from those achieved after 100 grams of glucose. However, elevated plasma levels maintained longer after 100 grams than after 50 grams, corresponding to the prolonged flow and absorption of nutrients in the small intestine. GIP plasma levels were still maxi- 

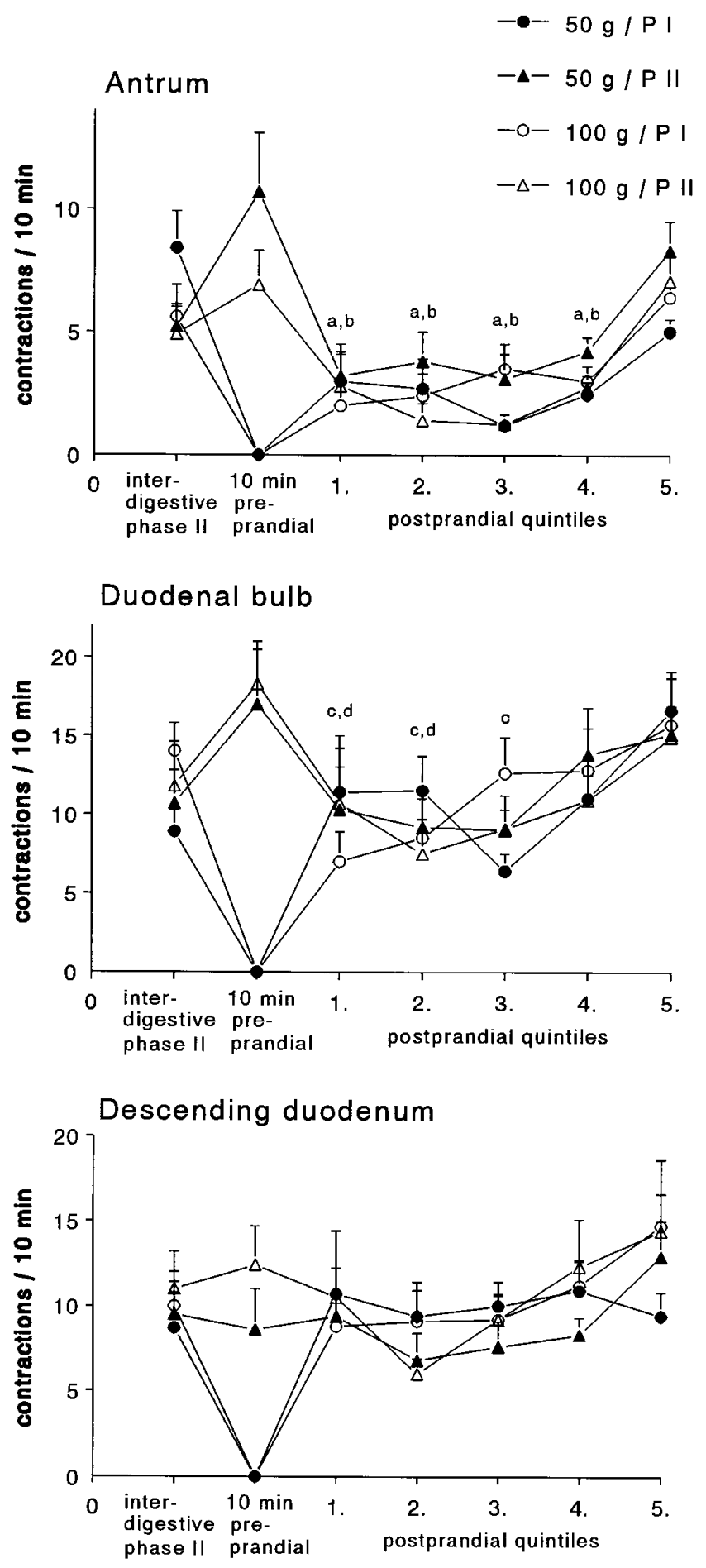

Figure 3. Contraction frequencies in antrum (top), duodenal bulb (middle), and descending duodenum (bottom) after ingestion of 50 and 100 grams of glucose in interdigestive phase I $(P I)$ or phase II $(P I I)$ in eight volunteers. Given are time courses during preprandial interdigestive phase II, 10 min preprandially, and the postprandial period with the latter subdivided into five quintiles. Mean \pm SEM. ${ }^{\mathrm{a}, \mathrm{b}} P<0.05$ indicating significant differences for 50 grams $(a)$ and 100 grams $(b)$, compared with both interdigestive phase II and the fifth postprandial quintile. ${ }^{\mathrm{c}, \mathrm{d}} P<0.05$ indicating significant differences for 50 grams $(c)$ and 100 grams $(d)$ compared with the fifth postprandial quintile.
A
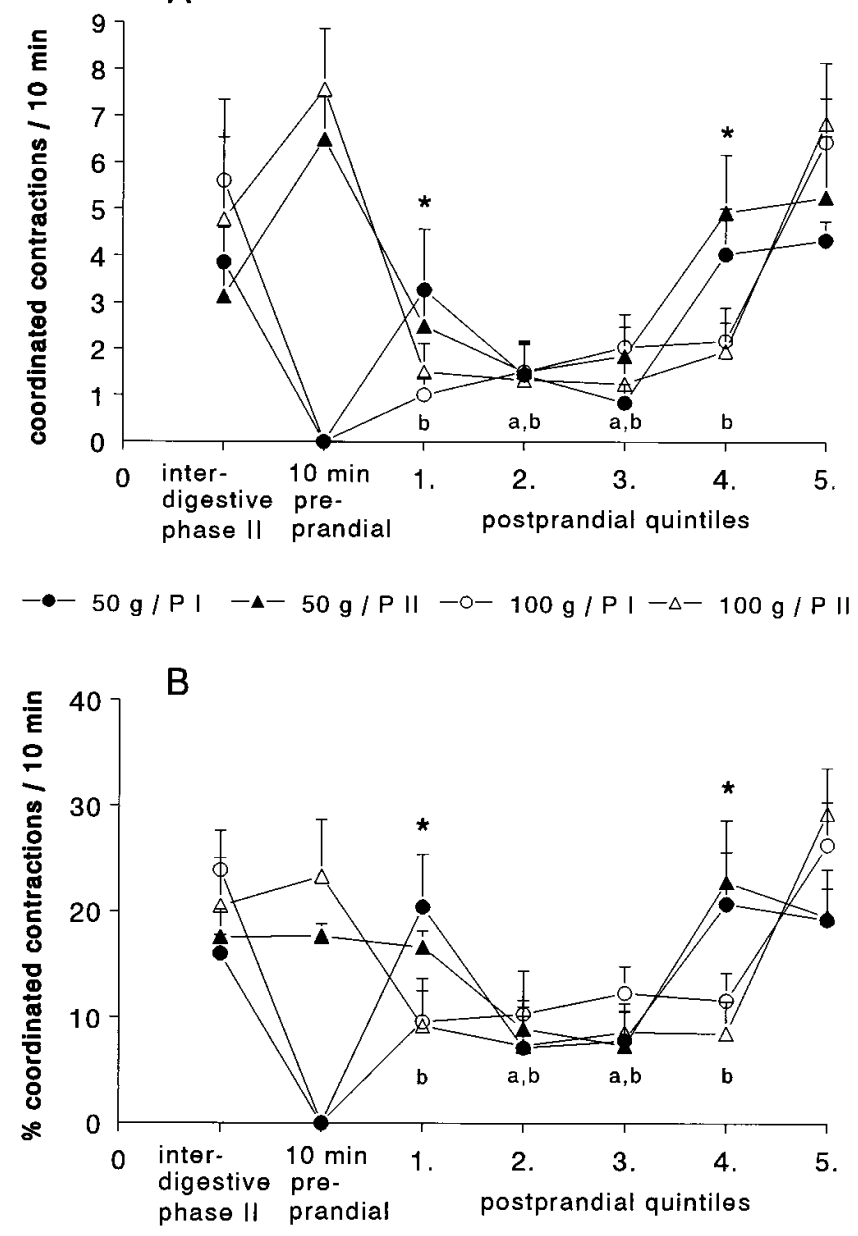

Figure 4. Number $(A)$ and percentage $(B)$ of antral contractions coordinated to duodenal peaks after ingestion of 50 and 100 grams of glucose in interdigestive phase I $(P I)$ or phase II $(P I I)$ in eight volunteers. Given are time courses during preprandial interdigestive phase II, 10 min preprandially, and the postprandial period with the latter subdivided into five quintiles. Mean \pm SEM. ${ }^{\mathrm{a}, \mathrm{b}} P<0.05$ indicating significant differences for 50 grams $(a)$ and 100 grams $(b)$, compared with both interdigestive phase II and the fifth postprandial quintile. ${ }^{*} P<0.05$, significant difference between experiments with 50 and 100 grams.

mal when glucose emptying rates dropped to $1.4 \pm 0.1 \mathrm{kcal} / \mathrm{min}$ (50 grams; $60 \mathrm{~min}$ postprandially) and $1.1 \pm 0.1 \mathrm{kcal} / \mathrm{min}(100$ grams; 120 min postprandially) (Fig. 6, $C$ and $D$ ). When IRGIP returned to basal levels with 50 grams, caloric delivery of glucose into the duodenum had almost ceased $(0.17 \pm 0.07$ $\mathrm{kcal} / \mathrm{min}$ ). By contrast, after 100 grams of glucose, GIP plasma levels remained significantly elevated over the whole emptying period. This prolonged GIP release would mirror ongoing intestinal glucose absorption.

Integrated values of IR-GLP-1, IR-GIP, and glucose delivery into the duodenum during the first postprandial hour over basal were tested for significant influences on the integrated incremental insulin response during this time period. Each of these parameters significantly correlated $(P<0.001)$ with integrated IR-insulin: $r=0.56$ for GLP-1, $r=0.55$ for GIP, and $r=0.62$ for glucose delivery. Stepwise and multiple linear re- 


\section{Plasma glucose}

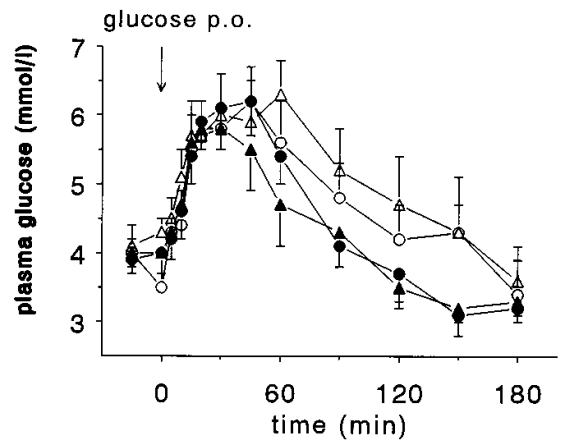

\section{GLP-1}

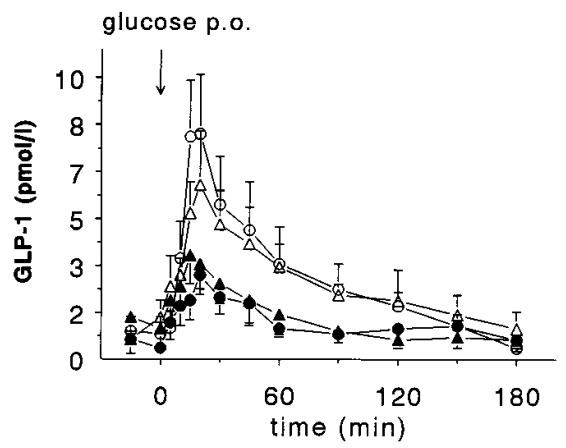

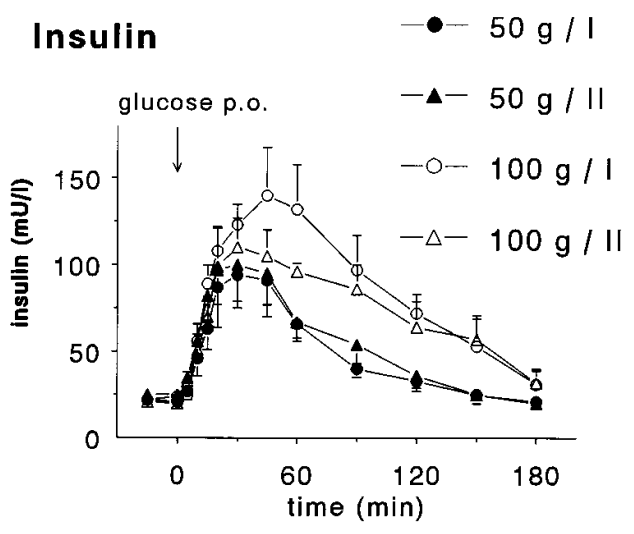

GIP
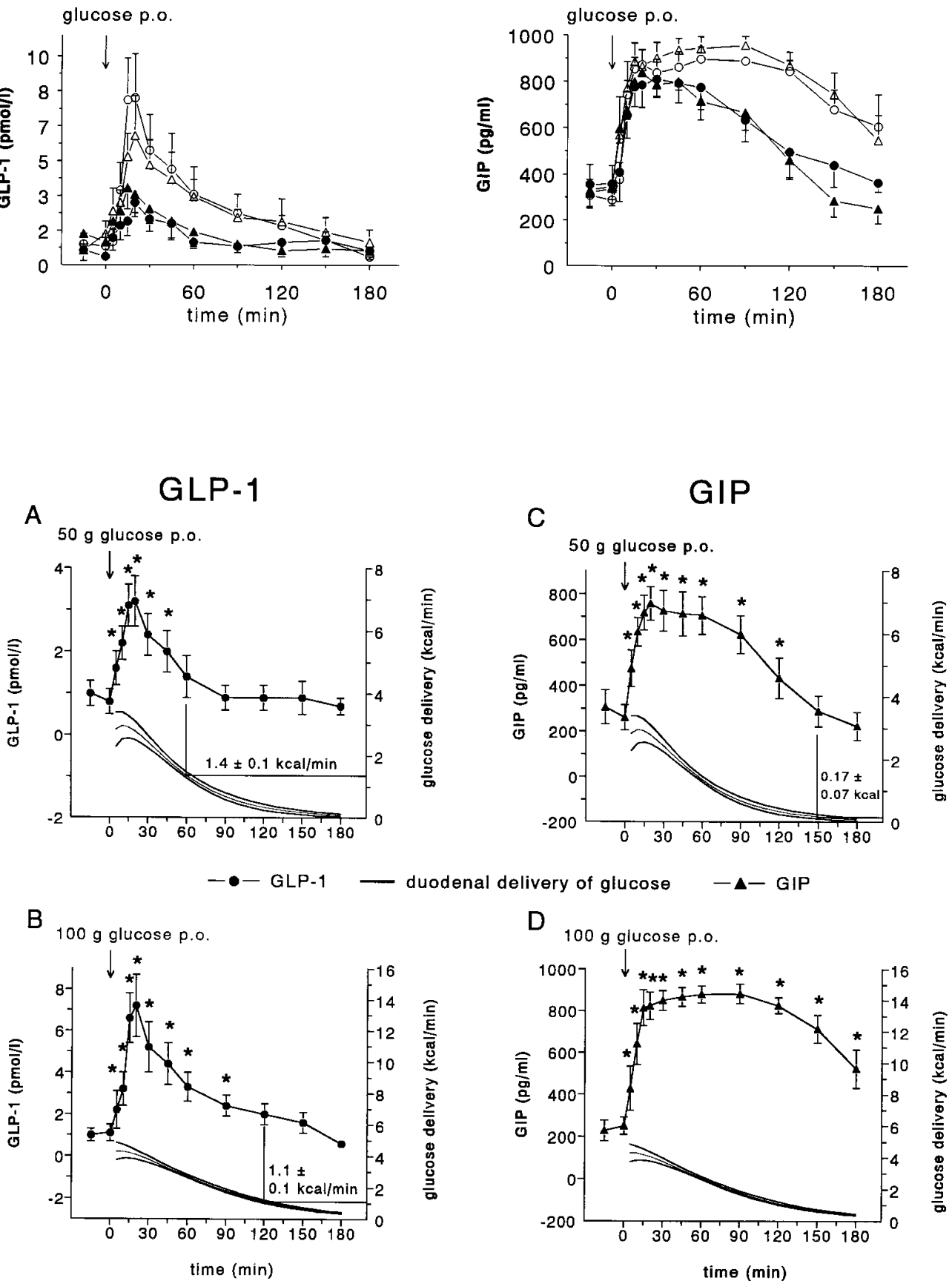

Figure 5. Responses of plasma glucose, insulin, immunoreactive GLP-1 (antibody GA 1178), and immunoreactive GIP to oral ingestion (arrows) of 50 and 100 grams of glucose in interdigestive phase I $(I)$ or phase II $(I I)$ in eight volunteers. Mean \pm SEM. For statistical analysis, see Figs. 7 and 8.
Figure 6. Responses of immunoreactive GLP-1 ( $A$ and $B$ ) and immunoreactive GIP $(C$ and $D)$ and delivery of glucose into the duodenum after oral ingestion (arrows) of 50 grams ( $A$ and $C$ ) and 100 grams $(B$ and $D)$ of glucose in eight volunteers. Mean \pm SEM. Deliveries of glucose into the duodenum (see Fig $2 A$ ) are displayed as means (central lines) \pm SEM (accompanying lines). $* P<0.05$ for significant differences compared with basal immunoreactivities. 
A

Plasma glucose
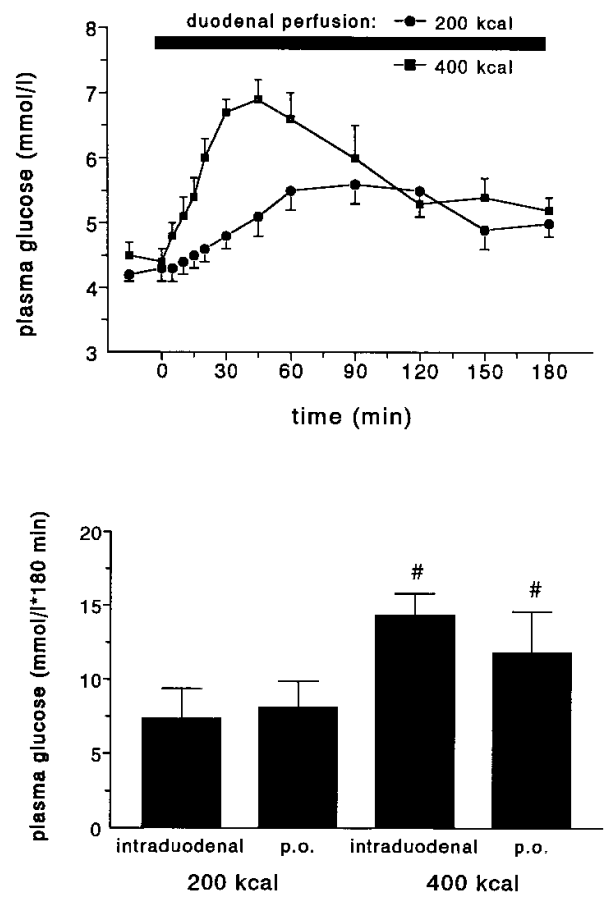

B

Insulin
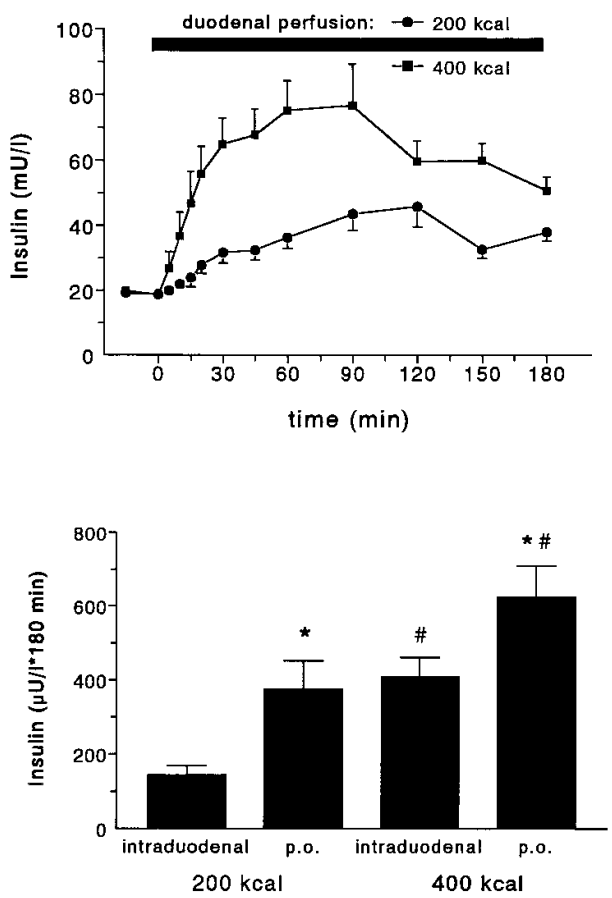

Figure 7. Plasma glucose levels $(A)$ and immunoreactive insulin $(B)$ in response to duodenal perfusion of glucose at $1.1 \mathrm{kcal} / \mathrm{min}$ $(=200 \mathrm{kcal} / 180 \mathrm{~min})$ and 2.2 $\mathrm{kcal} / \mathrm{min}(=400 \mathrm{kcal} / 180 \mathrm{~min})$ in eight volunteers. Areas under the glucose and IR-insulin response curves over basal, i.e., mean of values at -15 and $0 \mathrm{~min}$ (bottom), were compared for duodenal perfusion and oral ingestion of 200 and $400 \mathrm{kcal}$ of glucose. Mean \pm SEM. $* P<0.05$ for significant differences compared with intraduodenal perfusion of equicaloric glucose loads. ${ }^{\#} P<0.05$ indicating significant differences compared with 200 kcal glucose via the same route of application. gression analysis revealed a highly better correlation $(r=0.93)$ for all three parameters combined, with integrated IR-GLP-1 $(P=0.016)$, integrated IR-GIP $(P<0.001)$, and integrated glucose delivery $(P<0.001)$ independently associated with integrated IR-insulin during the first postprandial hour.

The integrated plasma glucose responses with duodenal perfusion and oral ingestion of identical amounts of glucose did not differ (Fig. $7 A$ ). Integrated IR-insulin was significantly higher with oral compared with duodenal administration of glucose (Fig. $7 \mathrm{~B}$ ). Correspondingly, integrated C-peptide release was higher $(P<0.05)$ with oral than duodenal glucose for 50 grams $(19.3 \pm 2.6$ vs. $11.5 \pm 1.1 \mathrm{ng} / \mathrm{ml} * 180 \mathrm{~min})$ and 100 grams $(32.1 \pm 3.6$ vs. $22.0 \pm 1.5 \mathrm{ng} / \mathrm{ml} * 180 \mathrm{~min})$.

Duodenal perfusion of glucose elicited a constant, loaddependent GIP release with the plateau achieved after 30 (1.1 $\mathrm{kcal} / \mathrm{min}$ ) and $15 \mathrm{~min}(2.2 \mathrm{kcal} / \mathrm{min})$, respectively (Fig. $8 \mathrm{~B})$.
A
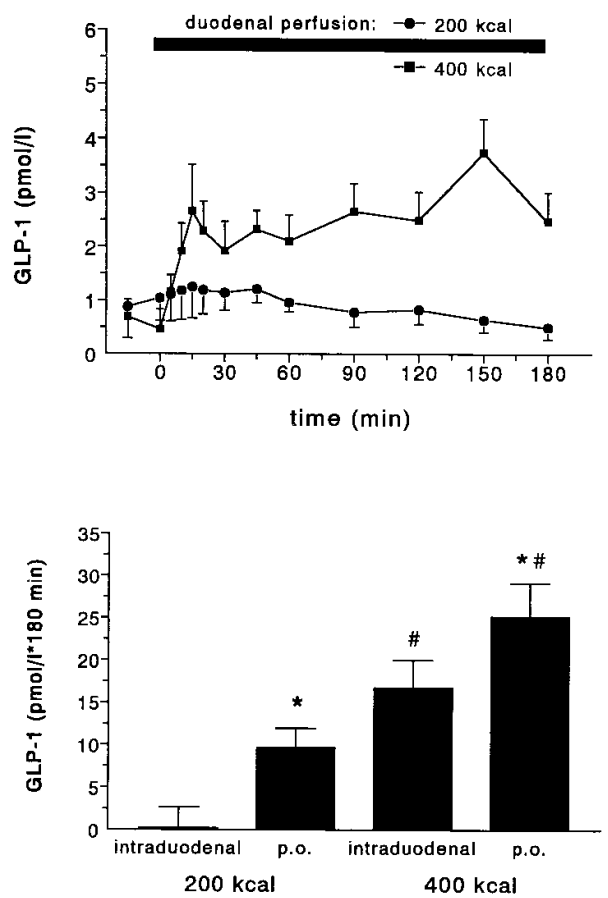

B
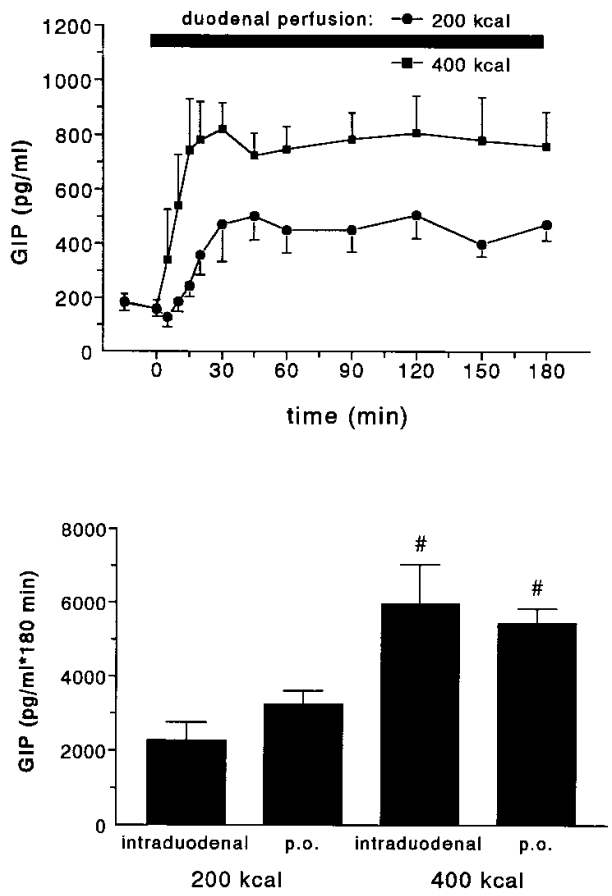

Figure 8. Immunoreactivities of GLP-1 $(A)$ and GIP $(B)$ in response to duodenal perfusion of glucose at $1.1 \mathrm{kcal} / \mathrm{min}(=200$ $\mathrm{kcal} / 180 \mathrm{~min})$ and $2.2 \mathrm{kcal} / \mathrm{min}$ $(=400 \mathrm{kcal} / 180 \mathrm{~min})$ in eight volunteers. Areas under the glucose and IR-insulin response curves over basal, i.e., mean of values at -15 and $0 \mathrm{~min}$ (bottom), were compared for duodenal perfusion and oral ingestion of 200 and $400 \mathrm{kcal}$ of glucose. Mean \pm SEM. $* P<0.05$ for significant differences compared with intraduodenal perfusion of equicaloric glucose loads. ${ }^{\#} P<$ 0.05 indicating significant differences compared with $200 \mathrm{kcal}$ glucose via the same route of application. 
The lower duodenal glucose load failed to increase GLP-1 plasma levels, whereas the higher load brought about a steady state of GLP-1 release after $15 \mathrm{~min}$ (Fig. $8 \mathrm{~A}$ ). By contrast to GIP, a threshold delivery of $1.1 \mathrm{kcal} / \mathrm{min}$ into the duodenum had to be exceeded to release GLP-1. A comparable GIP release was induced by oral administration and duodenal perfusion of identical amounts of glucose (Fig. $8 \mathrm{~B}$ ). Oral administration of identical glucose loads yielded a markedly higher GLP-1 release than the duodenal route (Fig. $8 A$ ).

\section{Discussion}

The salient findings of this study on healthy volunteers were as follows: Gastric emptying of glucose solutions (0.125-0.25 grams $/ \mathrm{ml}$ ) of $400 \mathrm{ml}$ displayed a power exponential pattern with a short initial lag period. The rate of glucose delivery into the duodenum was not constant but exponentially declined over time. Increasing the gastric glucose load raised the rate of caloric delivery into the duodenum but nevertheless prolonged gastric emptying. Plasma immunoreactivities of GLP-1 increased dose-dependently with increasing amounts of ingested glucose. In contrast to GIP, a duodenal delivery of glucose exceeding $1.4 \mathrm{kcal} / \mathrm{min}$ was necessary to release GLP-1. Oral administration of glucose yielded higher GLP-1 and insulin releases but an equal GIP release compared with the isocaloric duodenal perfusion. Considering the glucose loads and ingested volumes of this study, gastric emptying of glucose and hormone release were independent of the interdigestive motility phase which existed at the time of glucose ingestion. Glucose loads of 200-400 kcal induced a fed motor pattern with reappearance of phase III after $\sim 95 \%$ of the meal had emptied.

Gastric emptying and antroduodenal motility. A previous work using the serial test meal method for measurement of gastric emptying (26) put forward the concept of a constant rate of glucose emptying of $2.13 \pm 0.08 \mathrm{kcal} / \mathrm{min}$ throughout the emptying period not depending on glucose loads (3). However, these authors reported data from two volunteers and their follow-up period of $90 \mathrm{~min}$ was too short to characterize the total gastric emptying pattern of glucose solutions (see Fig. $1 \mathrm{~A}$ ). This inappropriately short monitoring period may have mimicked a linear emptying pattern. Also using the serial test meal, Hunt et al. (6) found mean caloric deliveries of 3.3 and $4.0 \mathrm{kcal} / \mathrm{min}$ for the first $30 \mathrm{~min}$ and of 1.9 and $2.8 \mathrm{kcal} / \mathrm{min}$ for the second $30 \mathrm{~min}$ after ingestion of $400 \mathrm{ml}$ glucose with 0.5 and $1.0 \mathrm{kcal} / \mathrm{ml}$, respectively. These authors reported a linear positive relationship between meal energy density and caloric delivery to the duodenum. These data clearly argue against a constant emptying rate not depending on gastric glucose loads. In the present study, there was a nonlinear relationship between caloric density and emptying rate (see Fig. $1 \mathrm{~B}$ ). This phenomenon was mainly due to initial retardation and later acceleration of volume emptying from the stomach.

In contrast to the serial test meal, the method assessing gastric emptying used in this study (20) continuously monitors gastric emptying in each subject. Moreover, this is the first study on glucose emptying where intragastric glucose concentrations were determined, thus describing the emptying of glucose itself. A shape of the emptying curve $\beta>1$ indicates an initial delay or slowing of emptying of the meal. Thus, highcaloric liquid meals containing glucose, fat, amino acids, or al- bumin $(27,28)$ follow an intermediate emptying pattern compared with the exponential emptying pattern of nonnutrient liquids $(\beta=1)$, the rapid initial emptying in patients with vagotomy and pyloroplasty $(\beta<1)$, and the prolonged lag phase with nearly absent emptying after ingestion of solids (17, 21, 22, 29).

The technique used in our study allows the simultaneous assessment of gastric emptying and secretion. The gastric secretory volumes after ingestion of 50 and 100 grams of glucose did not differ significantly. Thus, gastric secretion did not bias volume retained in the stomach with different glucose loads. Correspondingly, gastric glucose concentrations after the high-caloric glucose meal exceeded the values after the low-caloric meal throughout the whole emptying period. The increase in caloric delivery into the duodenum after the highcaloric meal during the first 60 min was caused by delivery of smaller volumes with a higher glucose concentration. After $100 \mathrm{~min}$, volumes emptied into the duodenum per sampling period were also larger with 100 grams of glucose (Fig. 2 C). Doubling the glucose concentration of the meal resulted in equal shapes of emptying curves but different emptying rates. The slower emptying rate with 100 grams would arguably be brought about by exposing a longer length of small intestine to nutrients, triggering more glucose sensors and initiating a stronger feedback inhibition of gastric emptying (30). In addition to osmoreceptors, these glucose-specific receptors are the major sensory mechanism mediating this feedback inhibition $(3,30)$.

In this study, the activity of interdigestive preprandial motor activity did not influence either the gastric emptying of the $400-\mathrm{ml}$ solutions of 50 or 100 grams of glucose or the resulting postprandial plasma glucose levels or the release of hormones. In contrast, Thompson et al. (2) reported reduced intragastric volumes at $30 \mathrm{~min}$ postprandially and higher plasma glucose levels after ingestion of 50 grams of glucose in interdigestive phase II compared with ingestion in antral motor quiescence. The most likely explanation for the differences compared with our results is the low volume of $200 \mathrm{ml}$ used in their study. The influence of interdigestive motility on liquid gastric emptying clearly depends on the volume administered (5); with increasing volumes the accelerating effect of antral activity at the time of liquid intake on the emptying rate diminishes compared with antral motor quiescence.

In our study, the postprandial motor pattern replaced the interdigestive motility regardless of the preceding interdigestive phase. Gastric emptying was controlled by the postprandial motility. Antral migrating motor complexes are a typical feature of the cyclical interdigestive pattern but are absent during the postprandial period. Irrespective of the caloric intake, these antral motor complexes occurred when $\sim 95 \%$ of the meal had emptied. This is an important novel finding of our study. These motor complexes indicate both the return of interdigestive motility and the approximate end of gastric emptying. Thus, migrating motor complexes, in addition to their known function as "housekeeper" cleaning the stomach of indigestible solids at the end of solid emptying (31), likewise terminate gastric emptying of caloric liquids.

In this study, antral contractile activity was inhibited to the same extent after ingestion of 50 and 100 grams of glucose, and duodenal activity remained unchanged compared with interdigestive motility. By contrast, the number of coordinated antroduodenal events was inhibited in a dose-dependent man- 
ner. This observation supports the concept that the rate of gastric emptying depends more on the spatial and temporal relationship of antral and duodenal contractions than on contraction frequency at a single site. Although it was technically impossible to additionally record fundic and pyloric motility in this study, we suggest that apart from the inhibition of coordinated antroduodenal contractions, reduction of fundic tone, elevation of pyloric tone, and stimulation of isolated pyloric pressure waves which are proven obstacles to transpyloric flow would contribute to the postprandial delay of gastric emptying (32-34).

Slowing of gastric emptying involves neural and humoral pathways. Isolated pyloric pressure waves induced by duodenal perfusion of dextrose in humans were inhibited by atropine indicating involvement of muscarinic receptors (35). The underlying mechanisms may be both activation of ascending, intramural cholinergic excitatory neurons (36) and stimulation of vagal excitatory input arguably via vagal glucoreceptors (37).

Acute hyperglycemia prolongs gastric emptying (38) and inhibits interdigestive antral motility in humans $(39,40)$. Since acute hyperglycemia suppressed efferent gastric vagal activity (41) and inhibited the release of pancreatic polypeptide, a marker of cholinergic tone (23), an interference of hyperglycemia with the activity of the cholinergic system may contribute to delayed gastric emptying. Since glucose plasma levels of 120 $\mathrm{mg} / \mathrm{dl}$ were sufficient to suppress antral phase III activity (39), it cannot be excluded that the physiological postprandial glucose plasma levels observed in the present study may have modified the antral motor response.

Cholecystokinin (CCK) is discussed as a candidate hormonal regulator of glucose emptying. Although plasma CCK concentrations increased only slightly after oral glucose, the CCK A receptor antagonist loxiglumide accelerated gastric emptying of glucose (28) and inhibited isolated pyloric pressure waves after duodenal perfusion of a mixed liquid meal (42). However, the pattern of glucose emptying under loxiglumide revealed that a high degree of small intestinal feedback inhibition was still operative (28). Endogenous CCK is not the major regulator of glucose emptying.

Oral ingestion of glucose markedly raises the plasma levels of GIP and GLP-1. Therefore, the role of these peptides as hormonal regulators of glucose emptying has to be discussed. So far no data are available which demonstrate an effect of GIP on gastric emptying in humans. Supraphysiological intravenous doses of GLP-1 inhibited gastric emptying (13). After preprandial subcutaneous injection of GLP-1 resulting in plasma immunoreactivities which peaked in the early postprandial state, we could show a dose-dependent prolongation of the lag period without any influence on the subsequent emptying period of a mixed liquid meal in healthy volunteers (14). In any case, endogenously released GLP-1 should be considered as an inhibitory regulator of gastric emptying. However, studies with a GLP-1 antagonist are needed to fully elucidate the physiological significance of GLP-1 in this context.

Release of incretin hormones. This is the first study characterizing the load-dependent release of GLP-1 in relation to the gastric emptying of glucose. GLP-1 plasma levels rose approximately from basal levels of $\sim 1 \mathrm{pmol} /$ liter to fourfold after ingestion of 50 grams of glucose and to eightfold after 100 grams, respectively. The magnitude of GLP-1 plasma levels reported here is in accordance with data published recently from our laboratory after oral ingestion of glucose and a mixed liquid meal (25). In the present study, IR-GLP-1 peaked in the early postprandial period at $20 \mathrm{~min}$ after glucose intake independent of the ingested glucose dose. Thereafter, IR-GLP-1 sharply declined depending on the amount of glucose ingested. Basal values were reached at $60 \mathrm{~min}$ after the low and $120 \mathrm{~min}$ after the high glucose load, respectively.

Similarly to IR-GLP-1, IR-GIP peaked at $\sim 20 \mathrm{~min}$ postprandially. However, in contrast to GLP-1, IR-GIP remained elevated over the whole gastric emptying period. This pattern of GIP release is in accordance with GIP secretion depending upon the rate of glucose absorption in the duodenum and upper jejunum and not the mere presence of nutrients in the small intestine (43).

To estimate the relative importance of GLP-1, GIP, and glucose delivery into the duodenum for the postprandial insulin release, stepwise and multiple regression analysis indicated all three parameters to be independently associated with insulin release during the first postprandial hour. The high correlation of $r=0.93$ for all three factors combined seems to characterize them as the crucial enteral determinants of postprandial insulin release after glucose intake.

The mechanisms by which ingested nutrients trigger GLP-1 release from intestinal $L$ cells are unknown. In each of the 32 experiments measuring gastric emptying, IR-GLP-1 declined to preprandial values independent of the oral glucose load when caloric delivery into the duodenum fell below $1.5 \mathrm{kcal} /$ min despite elevated plasma glucose and IR-GIP levels. To test this observation, we perfused glucose solutions directly into the duodenum applying the same total glucose load as orally administered in the gastric emptying experiments. Duodenal perfusion of glucose at $1.1 \mathrm{kcal} / \mathrm{min}$ did not stimulate GLP-1 release, whereas duodenal perfusion at $2.2 \mathrm{kcal} /$ min elicited a constant GLP-1 release after 15 min of perfusion. By contrast, GIP release was stimulated already by the low-caloric perfusion and rose with the high-caloric perfusion in a dose-dependent manner. Thus, the mere luminal presence or absorption of nutrients in the duodenum is insufficient to induce secretion of GLP-1. We suggest the existence of a threshold of caloric delivery into the duodenum which must be exceeded to stimulate measurable release of GLP-1 into the circulation. Oral administration of identical glucose loads yielded a markedly higher GLP-1 release than duodenal perfusion. In terms of 50 grams, the duodenal perfusion rate of 1.1 $\mathrm{kcal} / \mathrm{min}$ was insufficient to release GLP-1. In terms of 100 grams, the initially rapid gastric emptying of orally ingested glucose markedly exceeding duodenal deliveries of $2.2 \mathrm{kcal} /$ min most likely brought about the higher GLP-1 release. An alternative explanation would be the stimulation of GLP-1 release by gastric mechanisms such as gastric distension. However, studies on patients after total gastrectomy showing extremely high postprandial GLP-1 plasma levels due to rapid emptying of the gastric substitute (44) argue against a significant role of the stomach in mediating GLP-1 release. So far, no data are available proving the existence of a "gastric phase" of GLP-1 release. By contrast with GLP-1, comparable amounts of GIP were released after oral and duodenal glucose. GIP release is not directly related to gastric emptying but is governed by intestinal glucose absorption. The incretin effect in response to low duodenal glucose loads would be mainly mediated by GIP and not by GLP-1, which is not released by these low loads. The markedly higher insulin release by oral as com- 
pared with duodenal administration of glucose would be explained by distinctly higher releases of GLP-1.

The intraluminal presence of nutrients in isolated segments of the small intestine (25) and in the intact human ileum (45) can stimulate GLP-1 secretion. Here, contact of luminal nutrients with the luminal part of L cells is suggested to be involved in hormone release. GLP-1 secretory L cells are localized mainly in the distal part of the intestine, e.g., ileum, colon, and rectum; significant amounts of cells have also been found in the jejunum, but not in the duodenum (16).

Two mechanisms can be suggested to explain postprandial GLP-1 release. On the one hand, a threshold duodenal flow of glucose would be necessary to allow a minimum of glucose to escape the absorptive surface of the duodenum. This minimal amount of glucose would reach the proximal L cells and would be sufficient to stimulate GLP-1 release. However, the very rapid rise in GLP-1 levels observed after placement of glucose into the stomach, which was significant at $t=5 \mathrm{~min}$, casts doubt on the view that any jejunal cells significantly contribute to these increments. The absorptive capacity of the human duodenum for carbohydrates was shown to amount to 212 $\mathrm{mg} / \mathrm{min}(0.85 \mathrm{kcal} / \mathrm{min})$ to $359 \mathrm{mg} / \mathrm{min}(1.44 \mathrm{kcal} / \mathrm{min})$ depending on the osmolality of the nutrient perfusate (46). Already during the first $5 \mathrm{~min}$ of gastric emptying the rate of caloric delivery into the duodenum surpassed this absorptive capacity (see Fig. $1 \mathrm{~B}$ ). Thereafter, the time to reach maximal caloric delivery, the lag period (see Table I), was in good agreement with the time to maximal GLP-1 plasma levels; maximal duodenal flow rates coincided with maximal secretion of GLP1. Therefore, luminal stimulation of jejunal L cells by glucose may contribute to the rapid postprandial rise of IR-GLP-1.

On the other hand, most L cells are localized in more distal parts of the intestinal tract which are not exposed to luminal contact with nutrients during early postprandial GLP-1 release. Therefore additional factors, e.g., hormonal or neural signals, may be the dominant mechanism eliciting the rapid postprandial GLP-1 secretion. Then, a threshold rate of duodenal nutrient flow and/or nutrient absorption would initiate a neural and/or hormonal signal to the distal gut releasing GLP-1. In rats, GIP from the duodenal mucosa stimulated GLP-1 release, suggesting an enteroendocrine loop between the duodenum and more distal parts of the intestine (47). However, experiments in humans did not show any stimulation of GLP-1 secretion after exogenous infusion of GIP (48). The latter observation is in agreement with the present study showing no correlation between postprandial IR-GIP and IRGLP-1. CCK, released from duodenal mucosa by nutrients including glucose, can be ruled out as a mediator of GLP-1 release in humans, since a specific CCK antagonist failed to change insulin secretion in response to duodenal perfusion of a mixed meal $(49,50)$. In addition, CCK does not stimulate GLP-1 release from rat intestine in vitro (51) and in vivo (47). Cholinergic agonists as well as the neuropeptides gastrinreleasing peptide and calcitonin gene-related peptide have been reported to release GLP-1 from the isolated perfused rat ileum (52) and colon (53) when intraarterially infused. However, at this time no conclusive human data are available regarding the nature of the postulated signal to the distal gut.

The dependency of GLP-1 release on a threshold delivery of nutrients to the small intestine may provide GLP-1-induced insulin release when high insulin levels are needed, e.g., just in the early postprandial state, thus preventing hyperglycemia.
On the other hand, sharply declining GLP-1 release in the later postprandial period may serve as a safeguard against hypoglycemia.

\section{Acknowledgments}

The excellent technical assistance of Michaela Junck and Gabriele Kraft is gratefully appreciated.

This study was supported by a grant from the Deutsche Forschungsgemeinschaft (Ar 149/1-1).

\section{References}

1. McDonald, G. W., G. F. Fisher, and C. Burnham. 1965. Reproducibility of the oral glucose tolerance test. Diabetes. 14:473-480.

2. Thompson, D. G., D. L. Wingate, M. Thomas, and D. Harrison. 1982. Gastric emptying as a determinant of the oral glucose tolerance test. Gastroenterology. 82:51-55.

3. Brener, W., T. R. Hendrix, and P. R. McHugh. 1983. Regulation of the gastric emptying of glucose. Gastroenterology. 85:76-82.

4. Horowitz, M., M. A. L. Edelbroek, J. M. Wishart, and J. W. Straathof 1993. Relationship between oral glucose tolerance and gastric emptying in normal healthy subjects. Diabetologia. 36:857-862.

5. Oberle, R. L., T. S. Chen, C. Lloyd, J. L. Barnett, C. Owyang, J. Meyer, and G. L. Amidon. 1990. The influence of the interdigestive migrating motor complex on the gastric emptying of liquids. Gastroenterology. 99:1275-1282.

6. Hunt, J. N., J. L. Smith, and C. L. Jiang. 1985. Effect of meal volume and energy density on the gastric emptying of carbohydrates. Gastroenterology. 89: 1326-1330.

7. Cunningham, K. M., M. Horowitz, and N. W. Read. 1991. The effect of short-term dietary supplementation with glucose on gastric emptying in humans. Br. J. Nutr. 65:15-19.

8. Dupre, J., S. A. Ross, D. Watson, and J. C. Brown. 1973. Stimulation of insulin secretion by gastric inhibitory polypeptide in man. J. Clin. Endocrinol. \& Metab. 37:826-828.

9. Kreymann, B., M. A. Ghatei, G. Williams, and S. R. Bloom. 1987. Glucagon-like peptide-1 7-36: a physiological incretin in man. Lancet. 2:1300-1305.

10. Fehmann, H. C., R. Göke, and B. Göke. 1995. Cell and molecular biology of the incretin hormones glucagon-like peptide-1 and glucose-dependent insulin releasing polypeptide. Endocr. Rev. 16:390-410.

11. Gutniak, M., C. Orskov, J. J. Holst, B. Ahren, and S. Efendic. 1992. Antidiabetogenic effect of glucagon-like peptide 1 (7-36) in normal subjects and patients with diabetes mellitus. N. Engl. J. Med. 326:1316-1322.

12. D'Alessio, D. A., S. E. Kahn, C. R. Leusner, and J. W. Ensinck. 1994. Glucagon-like peptide 1 enhances glucose tolerance both by stimulation of insulin release and by increasing insulin-independent glucose disposal. J. Clin. Invest. 93:2263-2266.

13. Wettergren, A., B. Schjoldager, P. E. Mortensen, J. Myhre, J. Christiansen, and J. J. Holst. 1993. Truncated GLP-1 (proglucagon 78-107-amide) inhibits gastric and pancreatic functions in man. Dig. Dis. Sci. 38:665-673.

14. Schirra J., M. Katschinski, P. Kuwert, U. Wank, R. Arnold, and B. Göke. 1995. Differential effects of subcutaneous GLP-1 on gastric emptying, insulin release and exocrine pancreatic secretion in man. Gastroenterology. 108: A1003.

15. Layer, P., J. J. Holst, D. Grandt, M. v. d. Ohe, M. Rünzi, and H. Goebell. 1994. Postprandial release of glucagon-like peptide-1 (GLP-1) is disturbed in pancreatic insufficiency. Digestion. 55:312-313a. (Abstr.).

16. Eissele, R., R. Göke, S. Willemer, H.-P. Hartus, H. Vermeer, R. Arnold, and B. Göke. 1992. Glucagon-like peptide-1 cells in the gastrointestinal tract and pancreas of rat, pig and man. Eur. J. Clin. Invest. 22:283-291.

17. Houghton, L. A., N. W. Read, R. Heddle, M. Horowitz, P. J. Collins, B. Chatterton, and J. Dent. 1988. Relationship of the motor activity of the antrum, pylorus, and duodenum to gastric emptying of a solid-liquid mixed meal. Gastroenterology. 94:1285-1291.

18. Hyden, S. 1952. A turbidimetric method for the determination of higher polyethylene glycols in biological materials. K. Lantbrukshögsk. Ann. 22:139145 .

19. Hobsley, M., and W. Silen. 1969. Use of inert marker (phenol red) to improve accuracy in gastric secretion studies. Gut. 10:787-795.

20. Malagelada, J.-R., G. F. Longstreth, W. H. J. Summerskill, and V. L. W. Go. 1976. Measurement of gastric functions during digestion of ordinary solid meals in man. Gastroenterology. 70:203-210.

21. Elashoff, J. D., T. J. Reedy, and J. H. Meyer. 1982. Analysis of gastric emptying data. Gastroenterology. 83:1306-1312.

22. Siegel, J. A., J.-L. Urbain, L. P. Adler, N. D. Charkes, A. H. Maurer, B. Krevsky, L. C. Knight, R. S. Fisher, and L. S. Malmud. 1988. Biphasic nature of gastric emptying. Gut. 29:85-89.

23. Katschinski, M., G. Dahmen, M. Reinshagen, C. Beglinger, H. Koop, R. 
Nustede, and G. Adler. 1992. Cephalic stimulation of gastrointestinal secretory and motor responses in humans. Gastroenterology. 103:383-391.

24. Eyre-Brook, I. A., R. Smallwood, and A. G. Johnson. 1984. Human antroduodenal motility, pyloric closure, and domperidone. Scand. J. Gastroenterol. 19(Suppl. 92):4-7.

25. Herrmann, C., R. Göke, G. Richter, H.-C. Fehmann, R. Arnold, and B. Göke. 1995. Glucagon-like peptide-1 and glucose-dependent insulin-releasing polypeptide plasma levels in response to nutrients. Digestion. 56:117-126.

26. Hunt, J. N., and W. R. Spurrell. 1951. The pattern of emptying of the human stomach. J. Physiol. (Lond.). 113:157-168.

27. Fried, M., J. B. Jansen, T. Harpole, I. L. Taylor, C. B. Lamers, T. Reedy, J. Elashoff, and J. H. Meyer. 1989. Pancreatobiliary responses to an intragastric amino acid meal: comparison to albumin, dextrose, and a maximal cholecystokinin stimulus. Gastroenterology. 97:1544-1549.

28. Fried, M., U. Erlacher, W. Schwizer, C. Löchner, J. Koerfer, C. Beglinger, J. B. Jansen, C. B. Lamers, F. Harder, A. Bischof-Delaloye, G. A. Stalder, and L. Rovati. 1991. Role of cholecystokinin in the regulation of gastric emptying and pancreatic enzyme secretion in humans. Gastroenterology. 101: 503-511.

29. Gulsrud, P. O., I. L. Taylor, H. D. Watts, M. B. Cohen, J. Elashoff, and J. H. Meyer. 1980. How gastric emptying of carbohydrates affects glucose tolerance and symptoms after truncal vagotomy with pyloroplasty. Gastroenterology. 78:1463-1471

30. Lin, H. C., J. E. Doty, T. J. Reedy, and J. H. Meyer. 1989. Inhibition of gastric emptying by glucose depends on length of intestine exposed to nutrient. Am. J. Physiol. 256:G404-G411.

31. Feldman, M., H. J. Smith, and T. R. Simon. 1984. Gastric emptying of solid radiopaque markers: studies in healthy subjects and diabetic patients. Gastroenterology. 87:895-902.

32. Heddle, R., B. W. Miedema, and K. A. Kelly. 1993. Integration of canine proximal gastric, antral, pyloric, and proximal duodenal motility during fasting and after a liquid meal. Dig. Dis. Sci. 38:856-869.

33. Tougas, G., M. Anvari, D. Richards, J. Dent, S. Somers, and G. W. Stevenson. 1992. Relation of pyloric motility to pyloric opening and closure in healthy subjects. Gut. 33:466-471.

34. Heddle, R., D. Fone, J. Dent, and M. Horowitz. 1988. Stimulation of pyloric motility by intraduodenal dextrose in normal subjects. Gut. 29:1349-1357.

35. Fone, D. R., M. Horowitz, J. Dent, N. W. Read, and R. Heddle. 1989. Pyloric motor response to intraduodenal dextrose involves muscarinic mechanisms. Gastroenterology. 97:83-90.

36. Allescher, H.-D., E. E. Daniel, J. Dent, and S. Somers. 1988. Extrinsic and intrinsic neural control of pyloric sphincter pressure in the dog. J. Physiol. (Lond.). 401:17-38.

37. Mei, N. 1978. Vagal glucoreceptors in the small intestine of the cat. $J$. Physiol. (Lond.). 282:485-506.

38. McGregor, I. L., R. Gueller, H. D. Watts, and J. H. Meyer. 1976. The ef- fect of acute hyperglycemia on gastric emptying in man. Gastroenterology. 70: 190-196.

39. Barnett, J. L., and C. Qwyang. 1988. Serum glucose concentration as a modulator of interdigestive gastric motility. Gastroenterology. 94:739-744.

40. Fraser, R., M. Horowitz, and J. Dent. 1991. Hyperglycaemia stimulates pyloric motility in normal subjects. Gut. 32:475-478.

41. Hirano, T., and A. Niijima. 1980. Effects of 2-deoxy-D-glucose and insulin on efferent activity in gastric nerve. Experientia. (Basel). 36:1197-1198.

42. Katschinski, M., C. Beglinger, S. Langbein, G. Dahmen, U. Wank, G. Adler, and R. Arnold. 1994. Intestinal phase of human antro-pyloro-duodenal motility: cholinergic and CCK-mediated regulation. Dig. Dis. Sci. 39:1774a. (Abstr.)

43. Ebert, R., and W. Creutzfeldt. 1980. Decreased GIP through impairment of absorption. Front. Horm. Res. 7:192-201.

44. Miholic, J., C. Orskov, J. J. Holst, J. Kotzerke, and H. J. Meyer. 1991 Emptying of the gastric substitute, glucagon-like peptide (GLP-1), and reactive hypoglycemia after total gastrectomy. Dig. Dis. Sci. 36:1361-1370.

45. Layer, P., J. J. Holst, D. Grandt, and H. Goebell. 1995. Ileal release of glucagon-like peptide-1 (GLP-1). Association with inhibition of gastric acid secretion in humans. Dig. Dis. Sci. 40:1074-1082.

46. Pfeiffer, A., T. Schmidt, N. Vidon, and H. Kaess. 1993. Effect of ethanol on absorption of a nutrient solution in the upper human intestine. Scand. J. Gastroenterol. 28:515-521.

47. Roberge, J. N., and P. L. Brubaker. 1993. Regulation of intestinal proglucagon-derived peptide secretion by glucose-dependent insulinotropic peptide in a novel enteroendocrine loop. Endocrinology. 133:233-240.

48. Nauck, M. A., M. M. Heimesaat, C. Orskov, J. J. Holst, R. Ebert, and W. Creutzfeldt. 1993. Preserved incretin activity of glucagon-like peptide 1 [7-36 amide] but not of synthetic human gastric inhibitory polypeptide in patients with type 2 diabetes mellitus. J. Clin. Invest. 91:301-307.

49. Hildebrand, P., J. W. Ensinck, S. Ketterer, F. Delco, S. Mossi, U. Bangerter, and C. Beglinger. 1991. Effect of a cholecystokinin antagonist on meal stimulated insulin and pancreatic polypeptide release in humans. J. Clin. Endocrinol. \& Metab. 72:1123-1129.

50. Schwarzendrube, J., M. Niederau, R. Lüthen, and C. Niederau. 1991. Effects of cholecystokinin-receptor blockade on pancreatic and biliary function in healthy volunteers. Gastroenterology. 100:1683-1690.

51. Brubaker, P. L. 1991. Regulation of intestinal proglucagon-derived peptide secretion by regulatory peptides. Endocrinology. 128:3175-3182.

52. Herrmann-Rinke, C., A. Vöge, M. Hess, and B. Göke. 1995. Regulation of glucagon-like peptide- 1 secretion from rat ileum by neurotransmitters and peptides. J. Endocrinol. 147:25-31.

53. Plaisancie, P., C. Bernard, J.-A. Chayvialle, and J.-C. Cuber. 1994. Regulation of glucagon-like peptide-1-(7-36)amide secretion by intestinal neurotransmitters and hormones in the isolated vascularly perfused rat colon. Endocrinology. 135:2398-2403. 